\title{
Analysis Technique on Water Permeability in Concrete with Cold Joint considering Micro Pore Structure and Mineral Admixture
}

\author{
Se-Jin Choi, ${ }^{1}$ Suk-Pyo Kang, ${ }^{2}$ Sang-Chel Kim, ${ }^{3}$ and Seung-Jun Kwon ${ }^{4}$ \\ ${ }^{1}$ Department of Architectural Engineering, Wonkwang University, 460 Iksan Daero, Iksan 570-749, Republic of Korea \\ ${ }^{2}$ Department of Architecture \& Interior Design, Woosuk University, 66 Jincheon, Daehakro 365-803, Republic of Korea \\ ${ }^{3}$ Department of Civil Engineering, Hanseo University, 46 Hanseo 1 Ro, Chungnam 356-953, Republic of Korea \\ ${ }^{4}$ Department of Civil and Environmental Engineering, Hannam University, 133 Ojeong-dong, Daedeok-gu, \\ Daejeon 306-791, Republic of Korea
}

Correspondence should be addressed to Seung-Jun Kwon; jjuni98@hannam.ac.kr

Received 16 April 2015; Revised 14 July 2015; Accepted 2 August 2015

Academic Editor: Luciano Lamberti

Copyright (C) 2015 Se-Jin Choi et al. This is an open access article distributed under the Creative Commons Attribution License, which permits unrestricted use, distribution, and reproduction in any medium, provided the original work is properly cited.

\begin{abstract}
Cold joint in concrete due to delayed concrete placing may cause a reduced shear resistance and increased water permeation. This study presents an analytical model based on the concept of REV (Representative Element Volume) to assess the effect of water permeability in cold joint concrete. Here, OPC (Ordinary Portland Cement) concrete samples with cold joint are prepared and WPT (Water Permeability Test) is performed on the samples cured for 91 days. In order to account for the effect of GGBFS (Granulated Ground Blast Furnace Slag) on water permeability, concrete samples with the same W/B (Water to Binder) ratio and $40 \%$ replacement ratio of GGBFS are tested as well. Utilizing the previous models handling porosity and saturation, the analysis technique for equivalent water permeability with effective cold joint width is proposed. Water permeability in cold joint increases to $140.7 \%$ in control case but it decreases to $120.7 \%$ through GGBFS replacement. Simulation results agree reasonably well with experimental data gathered for sound and cold joint concrete.
\end{abstract}

\section{Introduction}

Concrete as a construction material has been widely used for its many advantages like cost-benefit, stable material supply, and high durability. The embedded steel in concrete plays an important role in RC (Reinforced Concrete) structures since concrete has very low strength and resistance to fracture in tensile regions [1]. Pores in concrete are the main routes for ingress of harmful ions $\left(\mathrm{Cl}^{-}\right.$and $\left.\mathrm{CO}_{2}\right)$ and water permeation, which usually causes rapid corrosion initiation of the embedded steel [2-4]. The durability problem starting with steel corrosion can propagate to degradation of structural safety. It can be observed as corrosion staining in outer concrete surface and is getting worse through cracking, spalling, and acceleration of corrosion and finally comes to collapse of RC structure due to reduced steel area and bond strength $[5,6]$. The pores and their connectivity are considered as major parameters for durability design and assessment since deteriorations like chloride attack and carbonation are quantitatively evaluated through pore structure system. Many models and techniques for chloride penetration and carbonation have been proposed considering micro pore structures $[3,4,7-9]$, which are supported by complicated physicochemical models and system dynamics considering cement hydration, moisture transport, and pore structure formation [10]. Several models have been developed by adopting both behaviors in early-aged concrete and special techniques such as neural network algorithm and genetic algorithm for representing reasonable mass transport and material behavior [11-14].

Cold joint occurs due to delayed placing of ready-mixed concrete, which causes reduced shear strength [15-17]. In mass concrete system or concrete with large unit content of binder, cold joint affects shear strength more severely and 


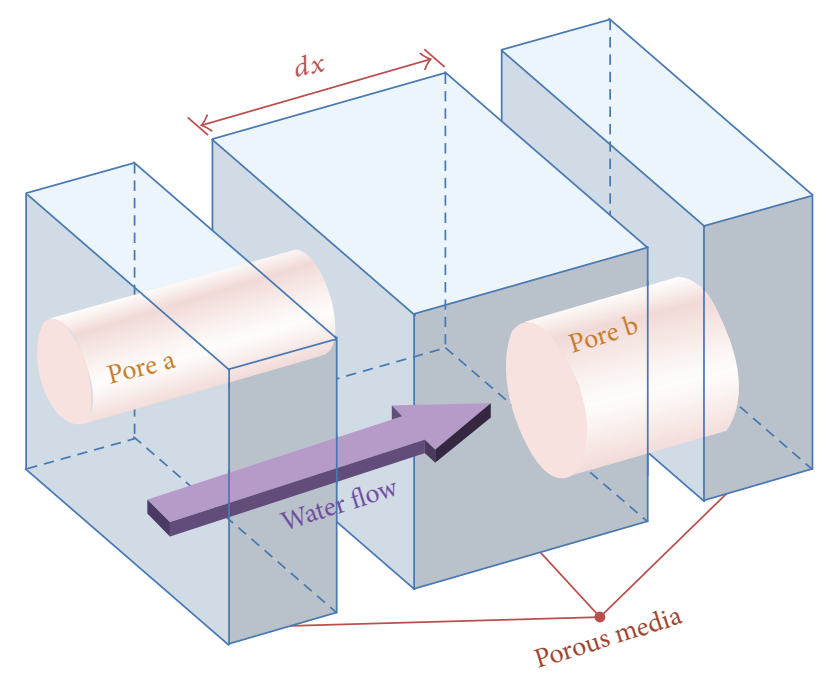

FIGURE 1: Water flow through concrete.

causes additional problem of durability. Ingress of harmful ions through cold joint area is reported to be more rapid than that in sound concrete, so that many researches analyzed carbonation, chloride attack, and water permeability in cold joint concrete [18-20]; however they mainly depend on field investigation results.

In the present paper, an analysis technique for water permeability in concrete with cold joint is proposed considering behavior in early-aged concrete like porosity and saturation. In particular concrete samples with cold joint are prepared and WPT (Water Penetration Test) is conducted based on the literature $[8,9,21]$. In order to assess the effect of mineral admixture on permeability, GGBFS is replaced with OPC (Ordinary Portland Cement) by $40 \%$. The previously developed models on early-aged concrete behavior are adopted to evaluate the equivalent water permeability in concrete with cold joint. The effects of cold joint and GGBFS on water permeation are analyzed and discussed in the paper.

\section{Water Permeation Behavior in Concrete as Porous Media}

2.1. Water Permeability without Cold Joint. The path for water permeation through concrete can be assumed to have several pipes with diameter of capillary pores like Figure 1. Total water flow through concrete is governed by the total porosity, and the transport rate depends on pore connectivity [9]. The water flow through pore and its system can be assumed as Figure 1 [9].

In the REV, total water flow $(Q)$ can be written as [9]

$$
Q=-\left(\int_{0}^{\infty} r_{i}^{2} \Omega_{i} d r_{i}\right) \frac{d P}{d x}
$$

where $\Omega_{i}$ and $r_{i}$ denote average area distribution function of pore $i$ and radius of individual pore, respectively. $d P / d x$

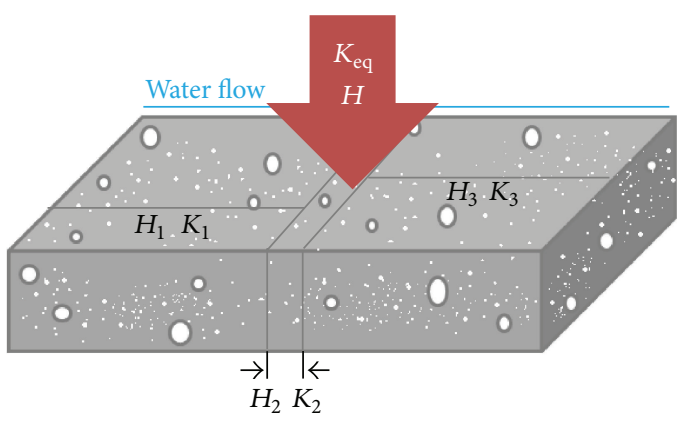

Figure 2: Water flow in REV with cold joint.

means fluid pressure gradient. Considering an equivalent pore radius for pores $(a$ and $b)$, (1) can be written as [9]

$$
Q=-\left(\frac{C}{8} \iint_{0}^{\infty} r_{\mathrm{eq}}^{2} d A_{a} d A_{b}\right) \frac{d P}{d x},
$$

where $r_{\mathrm{eq}}$ is equivalent pore radius. $d A_{i}$ and $C$ are pore area $\left(=\Omega_{i} d r_{i}\right)$ and constant. The relationship between volumetric porosity $(d V)$ and pore area $(d A)$ can be written as (3) [9]. Torturity factor $(n)$ can be assumed as $\pi^{2} / 4[9,10]$ so that (2) can be computed as (4) considering (3). Consider the following:

$$
\begin{aligned}
d V & =\frac{n d A}{\phi_{t}}, \\
k & =\frac{C \phi_{t}^{2}}{8}\left(\int_{0}^{\infty} r_{\mathrm{eq}} d V\right)^{2} .
\end{aligned}
$$

The calculation of integral term and $\phi_{t}$ (total porosity) is explained in Section 2.2 in detail.

\subsection{Modeling of Water Permeability in Concrete with Pore Structure and Cold Joint}

2.2.1. Modeling of Water Permeability in Parallel Direction. The REV with cold joint and normal concrete can be assumed as one member with two concrete plates $\left(H_{1}\right.$ and $\left.H_{3}\right)$ and joint area $\left(\mathrm{H}_{2}\right)$ in Figure 2 .

In the REV, total water flow $(Q)$ can be written as [22]

$$
Q=v_{1} H_{1}+v_{2} H_{2}+v_{3} H_{3} \text {. }
$$

$v_{i}$ and $H_{i}$ are average velocity and width of each layer $i$. Since $v_{1} H_{1}$ and $v_{3} H_{3}$ are the same, (5) can be written as (6) considering permeability coefficient $\left(K_{i}\right)$ in each layer of $i$. Water pressure gradients $\left(i_{\mathrm{eq}}, i_{1}\right.$, and $\left.i_{2}\right)$ are the same since water head of each section is constant, so that equivalent water permeability in total REV can be obtained as (7). Consider the following:

$$
\begin{aligned}
K_{\mathrm{eq}} i_{\mathrm{eq}} H & =2 K_{1} i_{1} H_{1}+K_{2} i_{2}\left(H-2 H_{1}\right), \\
K_{\mathrm{eq}} & =K_{2}+\frac{2 H_{1}}{H}\left(K_{1}-K_{2}\right),
\end{aligned}
$$

where $H$ is total width of REV, $K_{i}$ is water permeability of layer $i$ in Darcy's Law. 
2.2.2. Water Permeability considering Micro Pore Structure. In (4), intrinsic permeability is obtained. In order to solve (4), volumetric porosity and total porosity are needed. MTM (Moisture Transport Model) and MPSFM (Micro Pore Structure Formation Model) in Ducom (FE program) which can handle behavior in early-aged concrete such as porosity and saturation are utilized for calculation of volumetric and total porosity $[3,10-12]$. In the models, the interlayer porosity is simply lumped with the porosity distributions of gel and capillary porosity for obtaining the total porosity distribution of cement paste as [3]

$$
\begin{aligned}
\phi(r) & =\phi_{l r}+\phi_{c g}(r) \\
& =\phi_{l r}+\frac{1}{\phi_{c p}+\phi_{g l}}\left[\phi_{c p}(r)+\phi_{g l}(r)\right],
\end{aligned}
$$

where $\phi_{l r}$ and $\phi_{c g}$ are function of interlayer and capillary porosity, respectively. Utilizing Rayleigh-Ritz distribution function, porosity function is formulated as $[3,10]$

$$
\begin{aligned}
V_{i} & =1-\exp \left(-B_{i} r\right) \\
d V & =B_{i} r \exp \left(-B_{i} r\right) d \ln (r),
\end{aligned}
$$

where $V_{i}$ denotes the fractional pore volume of the distribution up to the pore radius and $B_{i}$ is the sole porosity distribution parameter for each pore of $i$. Total porosity can be obtained as (10) through constructing (8) and (9). For water transport, capillary pore governs water permeability so that capillary pore function, $\phi_{\mathrm{cp}}\left(B_{\mathrm{cp}}\right)$, is mainly considered like

$$
\phi_{\mathrm{cp}}\left(B_{\mathrm{cp}}\right)=\phi_{\mathrm{cp}}\left[1-\exp \left(-B_{\mathrm{cp}} r\right)\right] \text {. }
$$

The distribution parameter of $B_{\mathrm{cp}}$ can be obtained through MTM and MPSFM, which are based on the large number of data sets $[3,10]$.

Equation (4) for intrinsic permeability can be written as follows through constructing (10) [9]:

$$
\begin{aligned}
k & =\frac{C \phi_{\mathrm{cp}}^{2}}{8 n^{2}}\left(\int_{0}^{\infty} r \cdot B_{\mathrm{cp}} r \exp \left(-B_{\mathrm{cp}}\right) d r\right)^{2} \\
& =\frac{C \phi_{\mathrm{cp}}^{2}}{8 n^{2}}\left[\left.\exp \left(-B_{\mathrm{cp}} r\right) \cdot \frac{B_{\mathrm{cp}}+1}{B_{\mathrm{cp}}}\right|_{\infty} ^{0}\right]^{2} .
\end{aligned}
$$

After solving (11), water permeability of Darcy's Law is finally obtained as follows with constructing viscosity, density, and gravity $[3,9,10]$ :

$$
K=\frac{C \phi_{\mathrm{cp}}^{2}}{8 n^{2}} \frac{\rho g}{B_{\mathrm{cp}}^{2} \eta}
$$

where $\rho\left(999.3 \mathrm{~kg} / \mathrm{m}^{3}\right), g\left(9.81 \mathrm{~m} / \mathrm{sec}^{2}\right)$, and $\eta(1,764 \times$ $\left.10^{-6} \mathrm{~Pa} \cdot \mathrm{sec}\right)$ are fluid density, gravity acceleration, and fluid viscosity.

Water permeability values predicted by (12) are compared with experimental data.

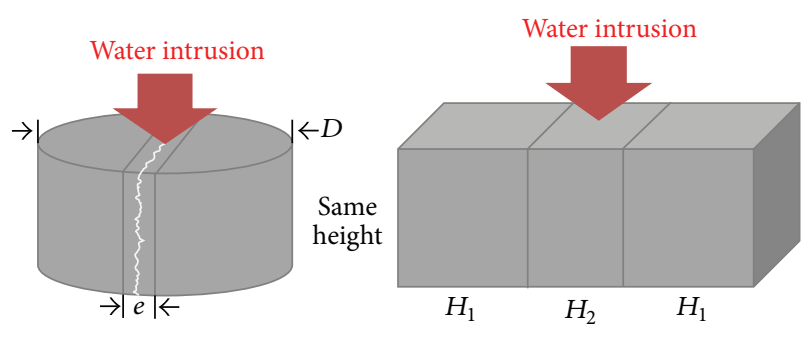

Figure 3: REV for actual water intrusion.

2.2.3. Derivation of Equivalent Water Coefficient in $R E V$ with Cold Joint. Equation (7) considers the presence of two different layers, where one is normal concrete and the other is cold joint area. The actual disk sample for WPT can be assumed as Figure 3 considering the concrete area exposed to water intrusion.

Assuming the effective width of cold joint which is vulnerable to water intrusion as parameter $e$, the cold joint area can be assumed as follows since $e$ is very small for the diameter of sample $(D)$ :

$$
A_{e}=D e
$$

Disk shaped REV (left in Figure 3) should have the same area as REV with cold joint (right in Figure 3), so that $H_{1}$ and $H_{2}$ can be calculated as follows when they have the same height:

$$
\begin{aligned}
& H_{1}=\frac{D e H}{\bar{A}}, \\
& H_{2}=\frac{(\bar{A}-D e) H}{2 \bar{A}},
\end{aligned}
$$

where $\bar{A}$ is the area of disk with cold joint $\left(=\pi D^{2} / 4\right)$.

Considering (14) in (7), equivalent diffusion coefficient $K_{\text {eq }}$ can be finally obtained as

$$
K_{\mathrm{eq}}=K_{2}+\frac{(\bar{A}-D e)\left(K_{1}-K_{2}\right)}{\bar{A}} .
$$

The simulation results obtained for different values of $K_{2}(0 \sim$ $10 E-10)$ and $e(0.05 \sim 0.20 D)$ are plotted in Figure 4.

\section{Experimental Program}

3.1. Experiment Outline. Cylindrical concrete samples with 0.6 of $\mathrm{w} / \mathrm{b}$ are prepared. OPC and $40 \%$ of GGBFS replacement ratio are selected for concrete mixing. After placing to cast a half volume, the samples are kept in room condition for 1 day, and then the half of cast is filled with the same mix proportions. After 1 day of air drying, the concrete sample is kept in water-submerged condition for 91 days. Water permeability is decreasing rapidly in early-aged concrete due to cement hydration $[8,9]$ so that long term curing period (91 days) is planned. After drying in room condition for 1 day, WPT is performed considering cold joint and GGBFS effect. The mix proportions are listed in Table 1 

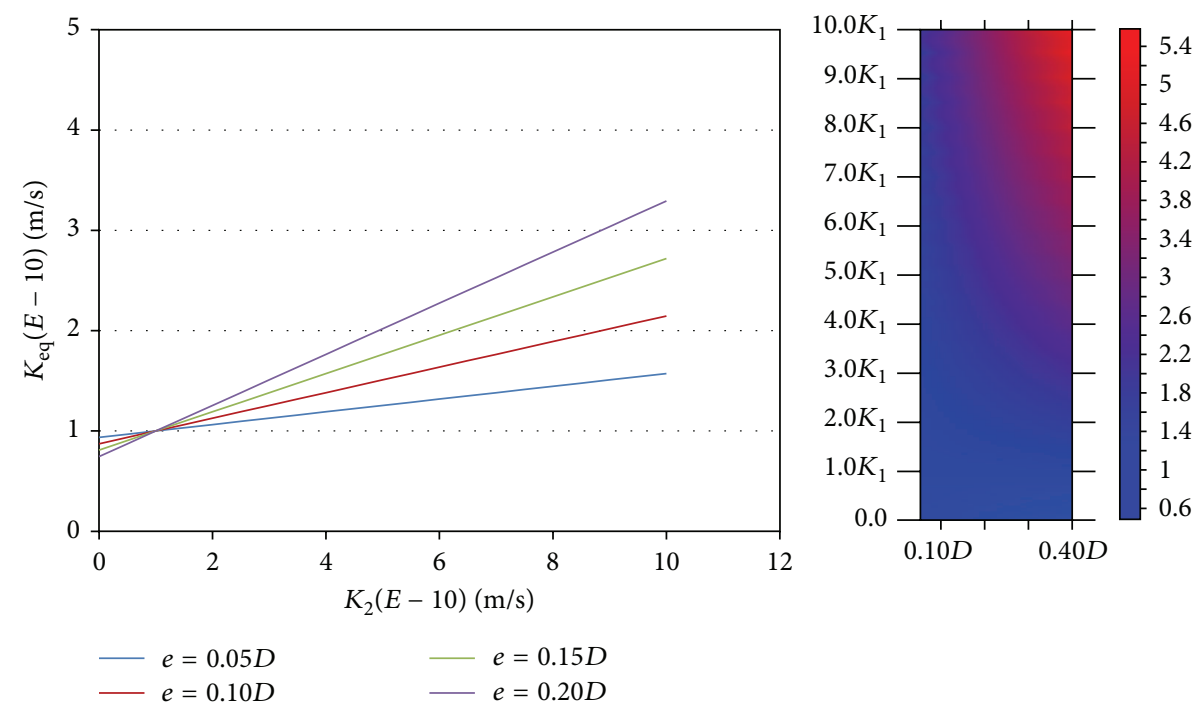

FIGURE 4: Equivalent water permeability with varying $K_{2}$ and $e$.

TABLE 1: Mix proportions for the test.

\begin{tabular}{|c|c|c|c|c|c|c|c|c|c|}
\hline \multirow{3}{*}{ Case } & \multirow{3}{*}{$G_{\max }(\%)$} & \multirow{3}{*}{ Slump (\%) } & \multirow{3}{*}{ S/a (\%) } & \multirow{3}{*}{ W/B (\%) } & \multicolumn{5}{|c|}{ Unit weight $\left(\mathrm{kg} / \mathrm{m}^{3}\right)$} \\
\hline & & & & & \multirow{2}{*}{$\mathrm{W}$} & & & \multirow{2}{*}{ S } & \multirow{2}{*}{ G } \\
\hline & & & & & & $\mathrm{C}$ & Slag & & \\
\hline OPC & \multirow{2}{*}{25} & \multirow{2}{*}{18} & \multirow{2}{*}{41.4} & \multirow{2}{*}{0.6} & \multirow{2}{*}{180} & 300 & - & \multirow{2}{*}{735} & 1040 \\
\hline GGBFS & & & & & & 180 & 120 & & 1020 \\
\hline
\end{tabular}

TABLE 2: Physical properties of fine and coarse aggregate.

\begin{tabular}{lcccc}
\hline Types & \multicolumn{5}{c}{$\begin{array}{c}\text { Items } \\
G_{\max } \\
(\mathrm{mm})\end{array}$} & $\begin{array}{c}\text { Specific gravity } \\
\left(\mathrm{g} / \mathrm{cm}^{3}\right)\end{array}$ & $\begin{array}{c}\text { Absorption } \\
(\%)\end{array}$ & FM \\
\hline Fine aggregate & - & 2.60 & 1.00 & 2.70 \\
Coarse aggregate & 25 & 2.62 & 0.78 & 6.78 \\
\hline
\end{tabular}

and physical properties of aggregates are listed in Table 2. Chemical compositions of OPC and GGBFS are listed in Table 3. The photos of samples with cold joint before WPT are shown in Figure 5.

3.2. Test Setup for Water Permeability. The water permeability of the joint is experimentally evaluated following the protocols documented in the literature $[8,9,21]$. Cylindrical concrete samples $(100 \times 200 \mathrm{~mm})$ are cut with $50 \mathrm{~mm}$ of height. The schematic arrangement of WPT is shown in Figure 6 with photo of test setup. WPT arrangement consists of two plastic cells fitted in steel frame. The water head is kept as $1,800 \mathrm{~mm}$, and the water drainage and head loss are measured, respectively. The concrete surface is coated with epoxy resin expect for supply (top) and drainage area of water (bottom).
The permeability coefficient by Darcy's Law can be derived from (16) assuming that water flow per unit time is constant due to steady state condition:

$$
\begin{aligned}
Q \frac{1}{d t} & =-\frac{A^{\prime} d H}{d t}=K_{p} \frac{H A}{L}, \\
-\frac{d H}{H} & =K_{p} \frac{A d t}{A^{\prime} L},
\end{aligned}
$$

where $K_{p}$ is permeability coefficient, $A$ and $A^{\prime}$ are area of concrete sample and water pipe, respectively. $L$ is thickness of the sample. The concrete upper surface with cold joint is perpendicular to water supply direction. The right term in (16) is integrated from initial water head $\left(H_{0}\right)$ to measured water head $\left(H_{1}\right)$, and the left term is integrated to measured time $(t)$. By integrating (17), water permeability coefficient is obtained as (18). Consider the following:

$$
\begin{aligned}
-\int_{H_{0}}^{H_{1}} \frac{d H}{d t} & =K_{p} \int_{0}^{t} \frac{A d t}{A^{\prime} L} \\
K_{p} & =\frac{A^{\prime} L}{A t} \ln \left(\frac{H_{0}}{H_{1}}\right) .
\end{aligned}
$$

The head loss and water drainage are measured at every 12 hours for 2 weeks. 
TABLE 3: Chemical compositions of OPC and GGBFS.

\begin{tabular}{lccccccccc}
\hline Composition & $\mathrm{SiO}_{2}(\%)$ & $\mathrm{Al}_{2} \mathrm{O}_{3}(\%)$ & $\mathrm{Fe}_{2} \mathrm{O}_{3}(\%)$ & $\mathrm{CaO}(\%)$ & $\mathrm{MgO}(\%)$ & $\mathrm{SO}_{3}(\%)$ & lg. loss (\%) & \multicolumn{2}{c}{$\begin{array}{c}\text { Physical properties } \\
\text { Specific gravity } \\
\text { Blaine }\left(\mathrm{cm}^{2} / \mathrm{g}\right)\end{array}$} \\
\hline OPC & 21.0 & 4.29 & 3.35 & 62.10 & 2.27 & 2.35 & 2.73 & 3.16 & 3,214 \\
GGBFS & 29.98 & 14.55 & 0.50 & 45.92 & 4.90 & 1.84 & 0.2 & 2.89 & 4,340 \\
\hline
\end{tabular}
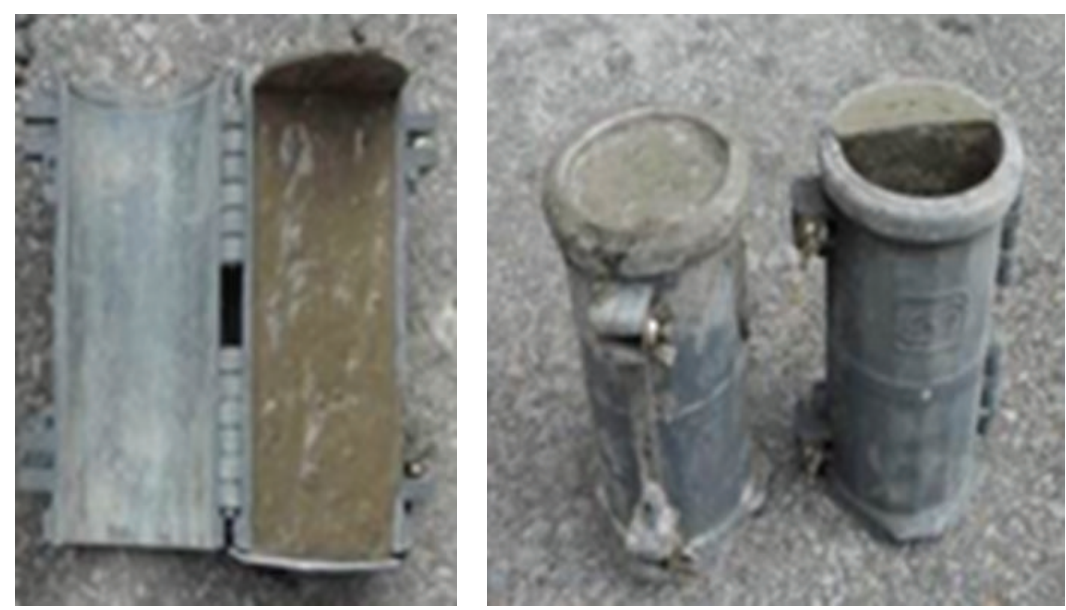

(a) Preparation of cold joint

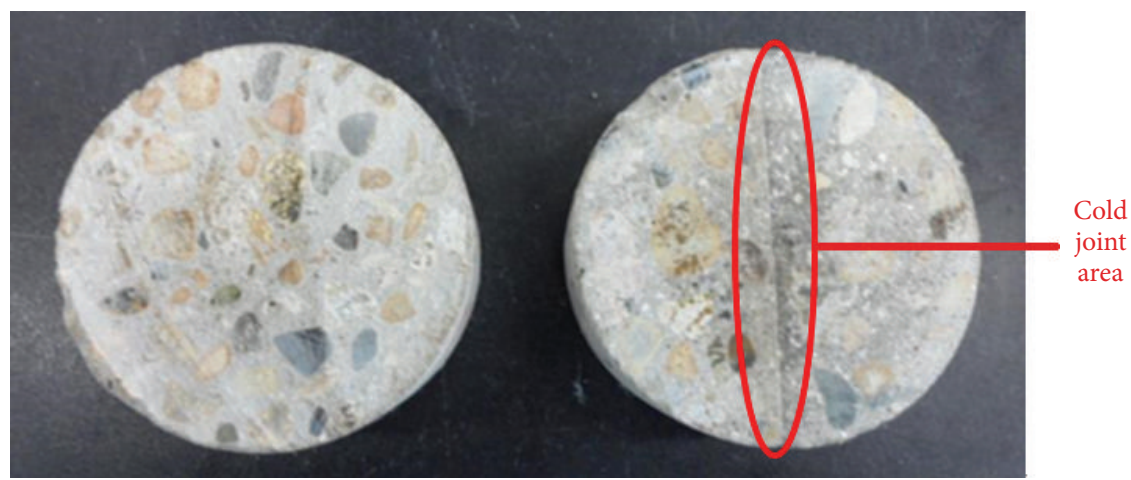

(b) Disk sample for WPT

Figure 5: Photos for concrete samples with cold joint.

\section{Evaluation of Water Permeability in Concrete}

4.1. Compressive Strength. Compressive strengths for OPC and GGBFS concrete are measured at 28 days and 91 days. For three samples for each case, average of test results is taken and plotted in Figure 7. Compressive strength in GGBFS concrete is lower than that in OPC concrete at 28 days but becomes definitely higher at 91 days. Latent hydration forming $\mathrm{CSH}$ (Calcium Silicate Hydrate) in GGBFS is the main mechanism for rapid strength development in long term period and it is reported as one of the most advantageous benefits in concrete with GGBFS $[12,23,24]$.

4.2. GGBFS and Cold Joint Effect on Water Permeability. The water permeability coefficient represents the water drainage velocity amount per unit time in a fixed area. In Figure 8, cumulative drained water is shown for OPC and GGBFS concrete. The ratios of drained water to control case (OPC without cold joint) are shown in Figure 9. Through replacing with GGBFS, water drainage decreases by $10.9 \%$ for normal concrete and by $14.1 \%$ for cold joint concrete. Compared with the result of OPC without cold joint, water drainage in OPC with cold joint increases by $47.9 \%$; however that in GGBFS with cold joint shows only $27.1 \%$ increment of water drainage.

The water permeability coefficients per measured period (12 hours) are plotted in Figure 10. The employed test has been performed for 2 weeks for the samples cured for 91 days. During the test period of 2 weeks, water is supplied every 12 hours and water permeability is calculated every 12 hours; then the average of permeability is plotted in Figure 10. The adopted test assumes constant water pressure and needs periodical water supply for keeping constant water level. In the test, water is manually supplied and the water drop is read every 12 hours, so permeability varies with every 12 hours. The small changes in temperature and mistakes 


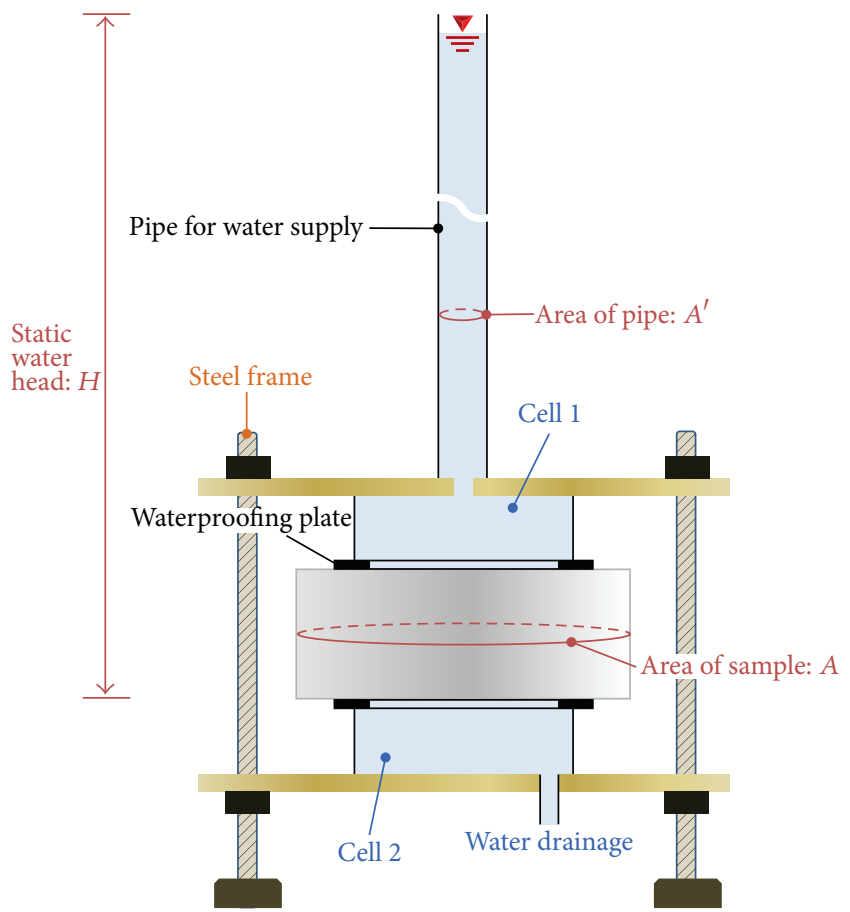

(a) WPT schematic diagram

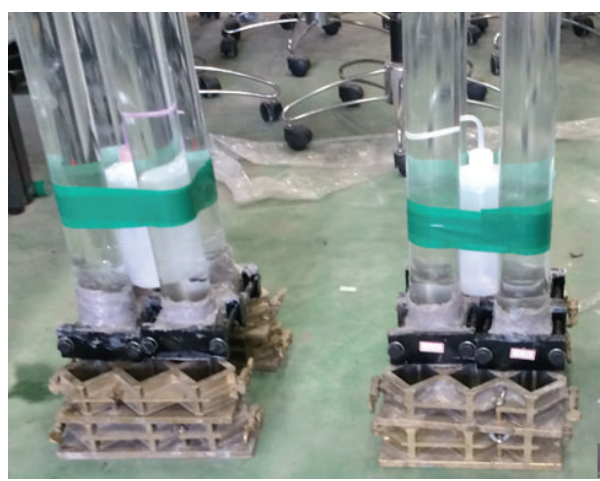

(b) WPT test setup

FIgURE 6: WPT schematic diagram and test setup.

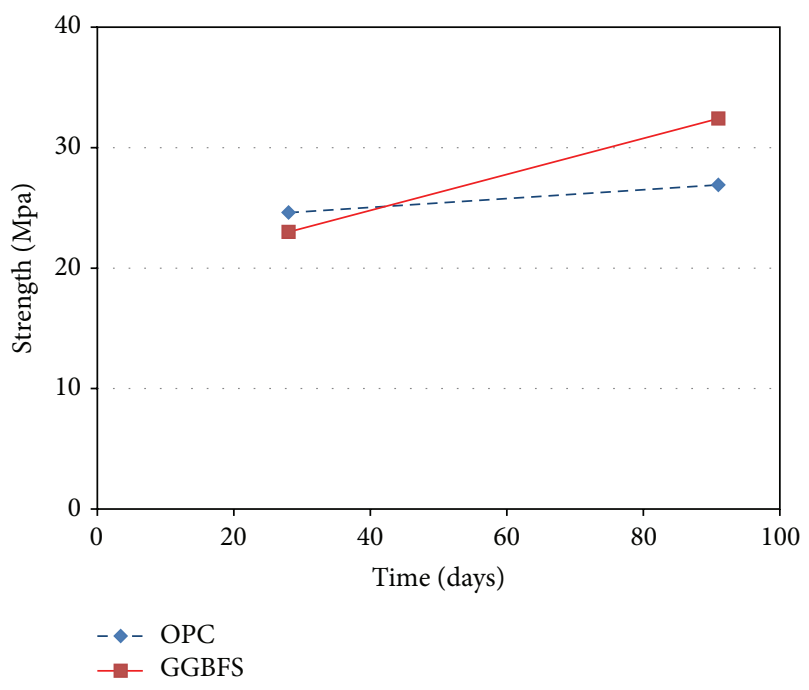

FIGURE 7: Compressive strength results at different ages.

in reading digit of water drainage may affect the water permeability calculation, but the effects are not significant compared with effects of GGBFS and cold joint. As shown in Figure 10, the calculated water permeability coefficients in every 12 hours show variations. It is reported in the literature that for a concrete with a $0.1 \mathrm{~mm}$ crack, water permeability coefficient increases to $230 \%$ [7]. Even if concrete has no crack, permeability may increase to $140 \%$ when OPC concrete

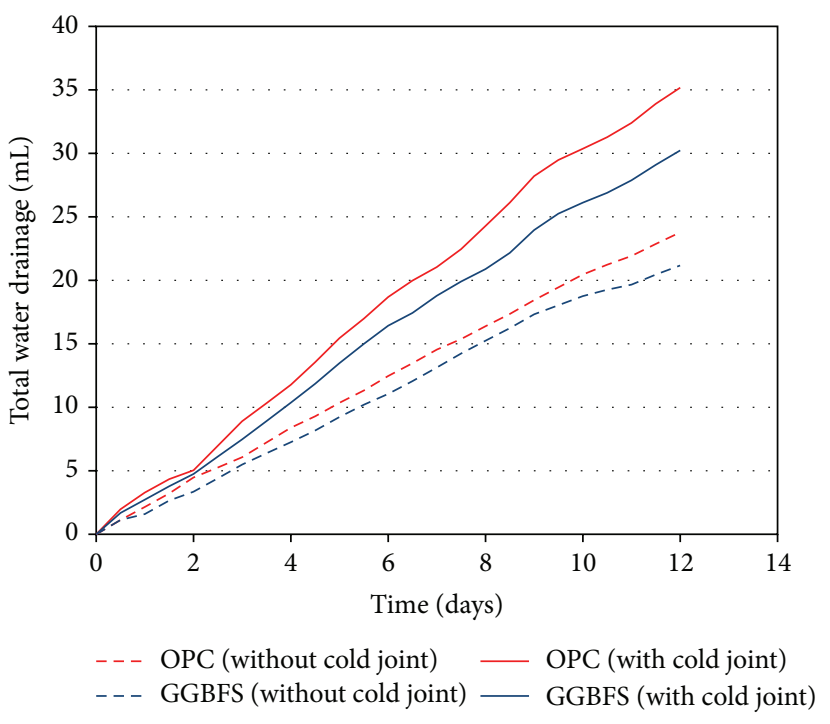

FIGURE 8: Cumulative water drainage over two weeks.

has cold joint as shown in Figure 11 which presents the ratios to control case (OPC concrete without cold joint).

Large variations in permeability are mostly caused by the limited number of samples considered in the experimental campaign. The more the samples prepared are, the more reliable and less scattered the results can be obtained through given standardized variables such as mean and deviation. 


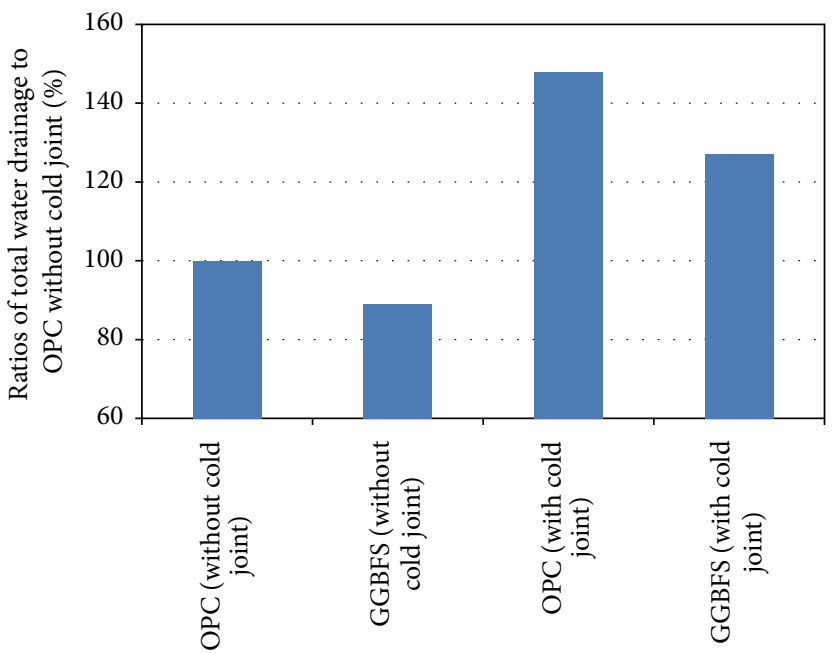

FIGURE 9: Ratios of water drainage to control case (after 2 weeks).

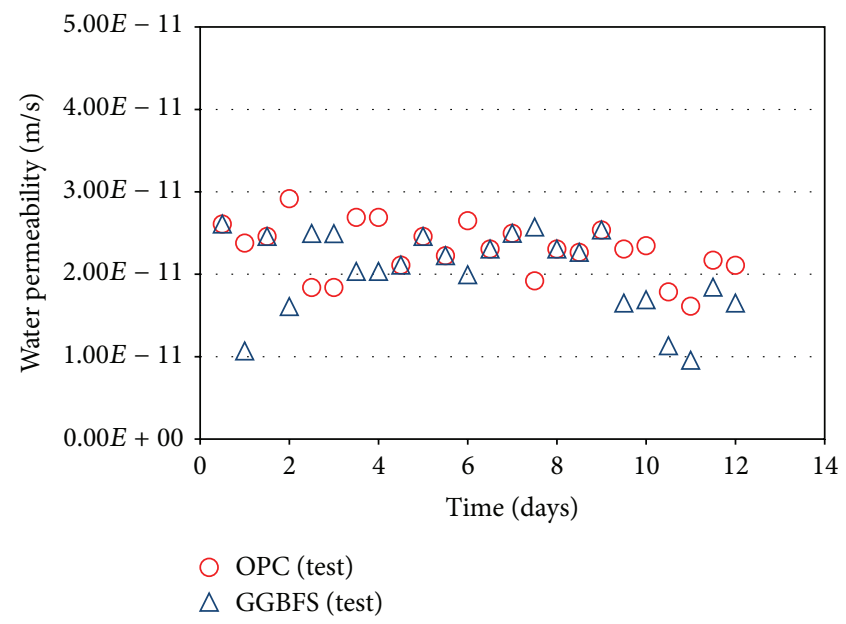

(a) Permeability coefficient in concrete without cold joint

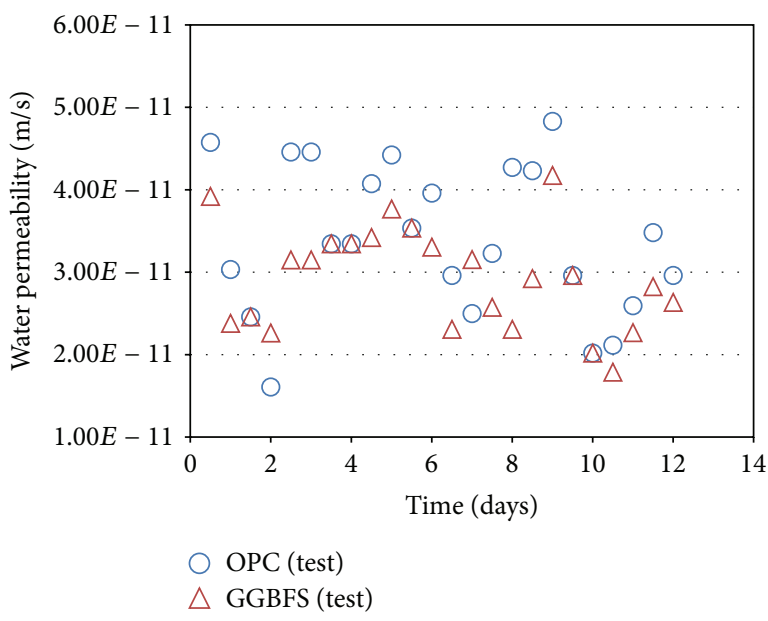

(b) Permeability coefficient in concrete with cold joint

FIGURE 10: Variations of the measured water coefficient in concrete.

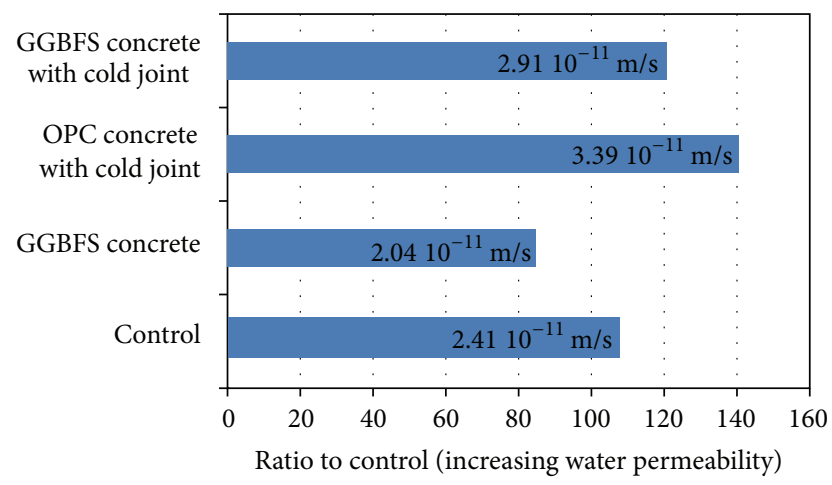

FIGURE 11: Ratios of water permeability to control case.

4.3. Comparison of Predicted Water Permeability Values with Experimental Data. In order to calculate the permeability of $K_{\mathrm{eq}}$ for each concrete (OPC and GGBFS concrete) with cold joint, (12) should be calculated firstly with porosity. The permeability coefficients are calculated through utilizing the results of DUCOM program. Input variables and boundary conditions are listed in Table 4 . The varying porosity which is the main parameter for water flow in concrete is shown in Figure 12, where porosity in GGBFS decreases more sharply after 7 days of curing.

Experimental data and simulation results are compared in Figure 13. For the analysis, the effective width $(e)$ and $K_{2}$ are assumed as $12 \mathrm{~mm}$ and $3.50 K_{1}$, respectively. The experimental constant $(C)$ is assumed as $9.8 E-3$ for OPC and $1.56 E-2$ for GGBFS. The variation of test results is not small; however the proposed technique shows a reasonable agreement with the average experimental data. Even if the WPT lasted 91 days, the permeability coefficients of test results are slowly decreasing due to hydration with time. The evolution of cumulative water drainage over two weeks 
TABLE 4: Input and boundary conditions for water permeability.

\begin{tabular}{lcccc}
\hline Initial temperature & Curing time & Exterior humidity & \multicolumn{2}{c}{ Capillary porosity and the related $B_{\text {cp }}$ at 91 days } \\
GGBFS
\end{tabular}

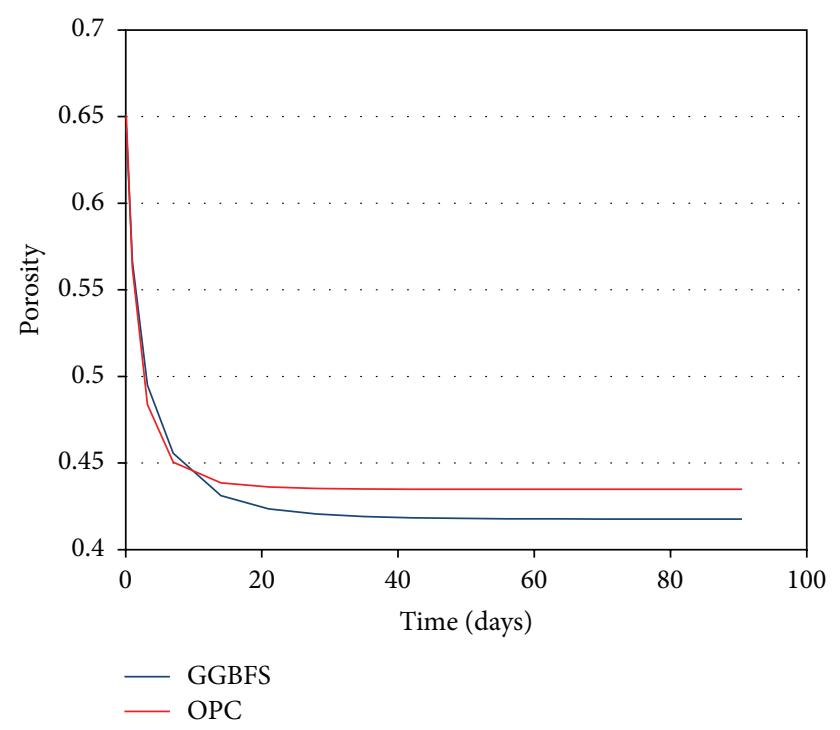

FIGURE 12: Changes in calculated porosity of GGBFS and OPC concrete.

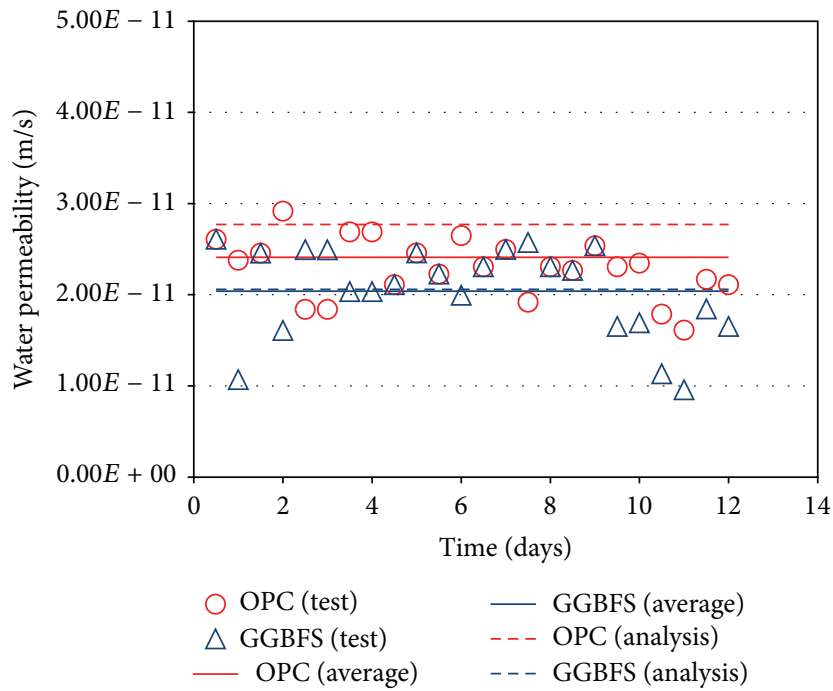

(a) Comparison of water permeability (without cold joint)

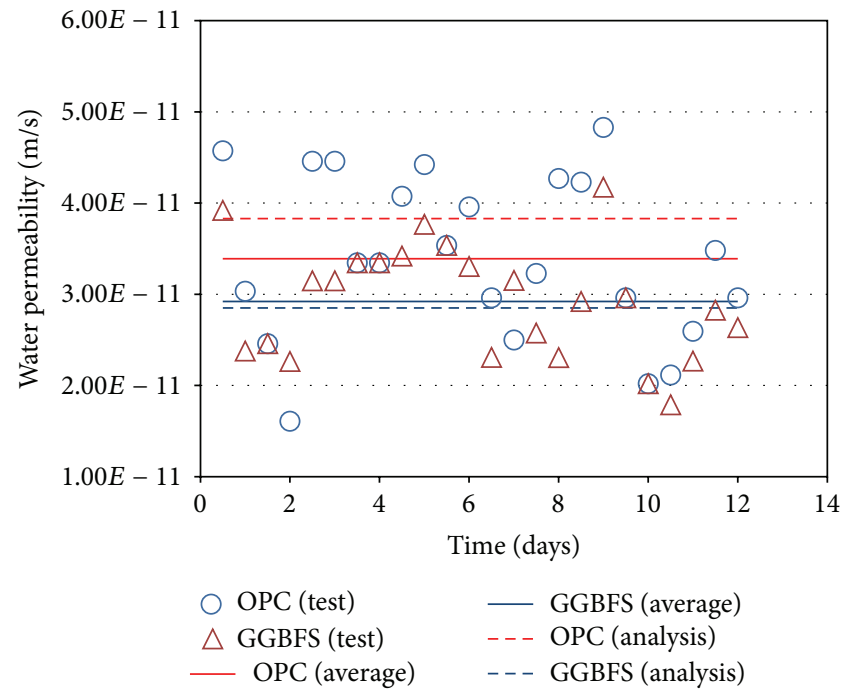

(b) Comparison of water permeability (with cold joint)

FIGURE 13: Comparison of water permeability.

is compared in Figure 14. The analytical model diverges from measured results in concrete without cold joint since constant $K$ at 91 days is adopted without time-dependency. The simulated results considering porosity with time effect are shown in Figure 15, where the reduced $K_{\text {eq }}$ due to pore densification of GGBFS and enlarged cold joint effect is noticeable, particularly, in the early age of the concrete.
As shown in Figure 14, the proposed model obtained very reasonable results. Relative errors with respect to measurements are $0.98 \sim 14.93 \%$ for normal concrete and -2.39 $12.97 \%$ for cold joint concrete, respectively. The prediction shows slight underestimation of water drainage in GGBFS concrete with cold joint. Since the porosity and $B_{\mathrm{cp}}$ parameter at 91 days are adopted in the analysis, the extended period 


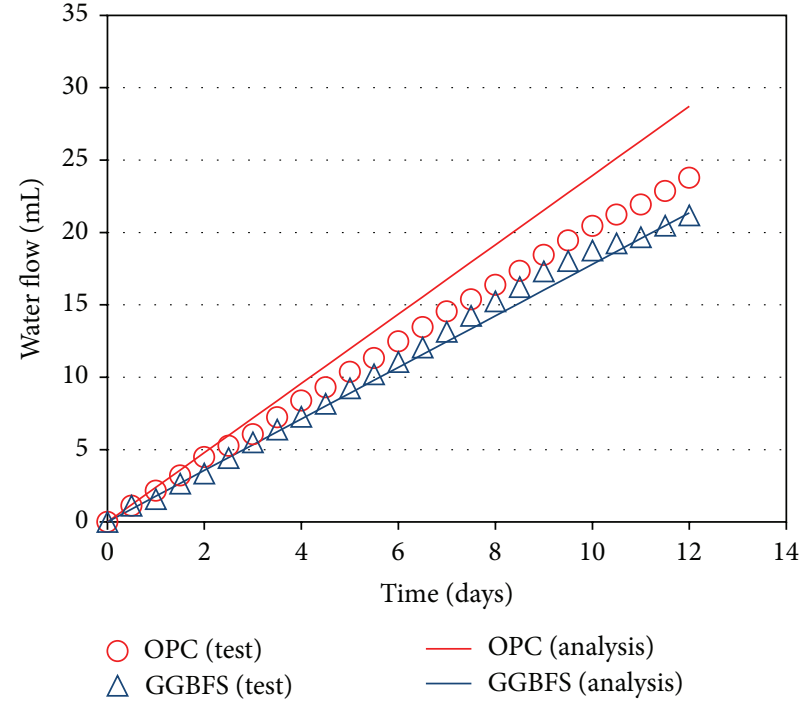

(a) Comparison of water flow (without cold joint)

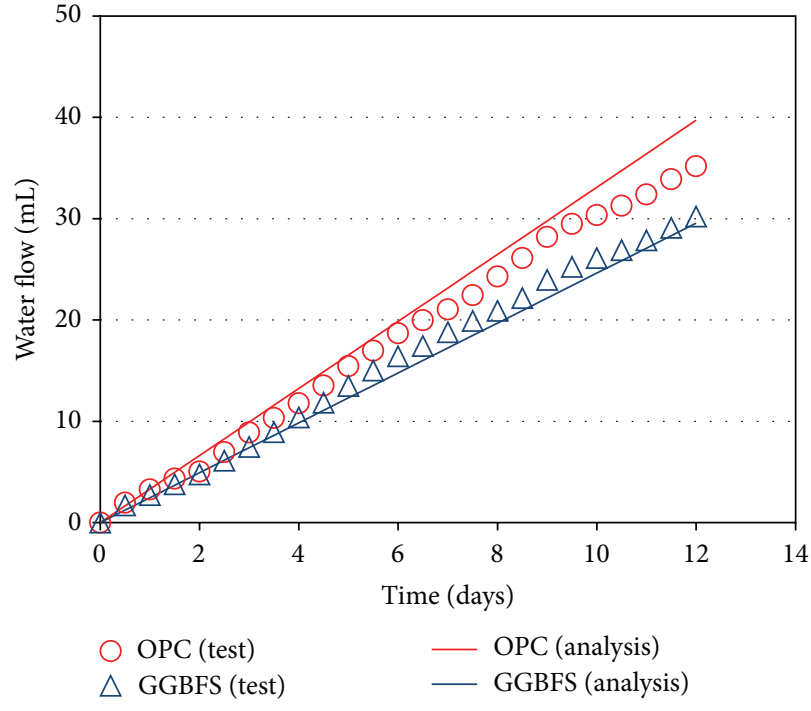

(b) Comparison of water flow (with cold joint)

FIGURE 14: Comparison of cumulative water flow.

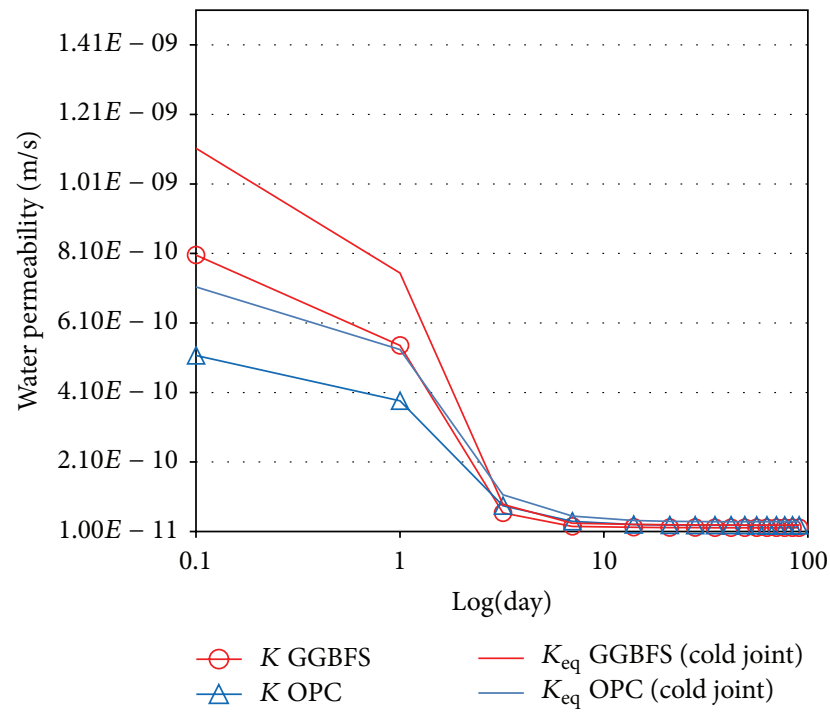

FIGURE 15: Simulated results of water permeability with time effect.

of test (for 2 weeks) is not considered for water permeability test. For the real structures exposed over 1 year, concrete will have almost the same pore structures and this can lead to almost constant water permeability. For the water permeability design using the proposed method, it is recommended to select porosity and parameter $B_{\mathrm{cp}}$ in the fully hydrated condition with 1.2 safety factor.

\section{Conclusions}

The conclusions on analysis technique on water permeability in cold joint concrete considering micro pore structure and mineral admixture are as follows.
(1) This study analyzed the effect of water permeability in cold joint concrete considering micro pore structure and mineral admixture of GGBFS. It was found that by replacing with GGBFS, water drainage decreases by $10.9 \%$ and $14.1 \%$ for normal concrete and cold joint concrete, respectively. Water drainage in OPC concrete with cold joint increases by $47.9 \%$ while GGBFS concrete allows such an increase limit to only $27.1 \%$ with respect to the control case.

(2) The analysis technique based on the use of a REV (Representative Element Volume) is quite effective as numerical results are in reasonable agreement with experimental observations: $0.98 \sim 14.93 \%$ and 2.39 12.97\% difference for normal and for cold joint concrete specimens, respectively.

\section{Conflict of Interests}

The authors declare that there is no conflict of interests regarding the publication of this paper.

\section{Acknowledgment}

This research was supported by Basic Science Research Program through the National Research Foundation of Korea (NRF) funded by the Ministry of Education (NRF2013R1A1A2060114).

\section{References}

[1] R. V. Silva, J. de Brito, and R. K. Dhir, "Tensile strength behaviour of recycled aggregate concrete," Construction and Building Materials, vol. 83, no. 5, pp. 108-118, 2015.

[2] A. Legat, "Monitoring of steel corrosion in concrete by electrode arrays and electrical resistance probes," Electrochimica Acta, vol. 52, no. 27, pp. 7590-7598, 2007. 
[3] T. Ishida and K. Maekawa, "Modeling of durability performance of cementitious materials and structures based on thermohygro physics," in Proceedings of the 2nd International RILEM Workshop on Life Prediction and Aging Management of Concrete Structures, vol. 1 of RILEM Proc-PRO29, pp. 39-49, Paris, France, May 2003.

[4] K. Maekawa, T. Ishida, and T. Kishi, "Multi-scale modeling of concrete performance," Journal of Advanced Concrete Technology, vol. 1, no. 2, pp. 91-126, 2003.

[5] O. E. Gjorv, "Durability design and construction quality of concrete structures," in Proceedings of the Conducting Business in a Regulatory Environment Conference (ConSec '04), vol. 1, pp. 44-55, 2004.

[6] J. P. Broomfield, Corrosion of Steel in Concrete: Understanding, Investigation and Repair, E\&FN, London, UK, 1997.

[7] S.-S. Park, S.-J. Kown, S. H. Jung, and S.-W. Lee, "Modeling of water permeability in early aged concrete with cracks based on micro pore structure," Construction and Building Materials, vol. 27, no. 1, pp. 597-604, 2012.

[8] S.-S. Park, S.-J. Kwon, and S. H. Jung, "Analysis technique for chloride penetration in cracked concrete using equivalent diffusion and permeation," Construction and Building Materials, vol. 29, no. 2, pp. 183-192, 2012.

[9] H.-W. Song and S.-J. Kwon, "Permeability characteristics of carbonated concrete considering capillary pore structure," Cement and Concrete Research, vol. 37, no. 6, pp. 909-915, 2007.

[10] K. Maekawa, T. Ishida, and T. Kishi, Multi-Scale Modeling of Structural Concrete, Taylor \& Francis, London, UK, 2009.

[11] V. Chandwani, V. Agrawal, and R. Nagar, "Modeling slump of ready mix concrete using genetic algorithms assisted training of Artificial Neural Networks," Expert Systems with Applications, vol. 42, no. 2, pp. 885-893, 2015.

[12] T. Ji, T. Lin, and X. Lin, "A concrete mix proportion design algorithm based on artificial neural networks," Cement and Concrete Research, vol. 36, no. 7, pp. 1399-1408, 2006.

[13] J. A. Stegemann and N. R. Buenfeld, "Prediction of unconfined compressive strength of cement paste with pure metal compound additions," Cement and Concrete Research, vol. 32, no. 6, pp. 903-913, 2002.

[14] K.-B. Park, T. Noguchi, and J. Plawsky, "Modeling of hydration reactions using neural networks to predict the average properties of cement paste," Cement and Concrete Research, vol. 35, no. 9, pp. 1676-1684, 2005.

[15] V. R. Rathi and P. K. Kolase, "Effect of cold joint on strength of concrete," International Journal of Innovative Research in Science, Engineering and Technology, vol. 2, pp. 4671-4679, 2013.

[16] JSCE, Concrete Cold Joint Problems and Countermeasures, vol. 103, Concrete Library Japan Society of Civil Engineeing, 2000.

[17] American Concrete Institute, ACI 224.3R-95, Joints in Concrete Construction, American Concrete Institute, Farmington Hills, Mich, USA, 2001.

[18] B. Sudret, G. Defaux, and M. Pendola, "Time-variant finite element reliability analysis-application to the durability of cooling towers," Structural Safety, vol. 27, no. 2, pp. 93-112, 2005.

[19] K. Yokozeki, K. Okada, T. Tsutsumi, and K. Watanabe, "Prediction of the service life of RC with crack exposed to chloride attack," Journal of Symposium: Rehabilitation of Concrete Structure, vol. 10, pp. 1-6, 1998.

[20] V. R. Rathi and P. K. Kolase, "Effect of cold joint on strength of concrete," International Journal of Innovative Research in Science, vol. 2, no. 9, 2013.
[21] D. Ludirdja, R. L. Berger, and J. F. Young, "Simple method for measuring water permeability of concrete," ACI Materials Journal, vol. 86, no. 5, pp. 433-439, 1989.

[22] B. M. Das, Principles of Geotechnical Engineering-Equivalent Hydraulic Conductivity in Stratified Soil, PWS Publishing Company, 1998.

[23] K. Metha and P. J. M. Monteiro, Concrete: Structure, Properties, and Materials, vol. 2, Prentice Hall, Upper Saddle River, NJ, USA, 1993.

[24] M. D. A. Thomas and P. B. Bamforth, "Modelling chloride diffusion in concrete: effect of fly ash and slag," Cement and Concrete Research, vol. 29, no. 4, pp. 487-495, 1999. 

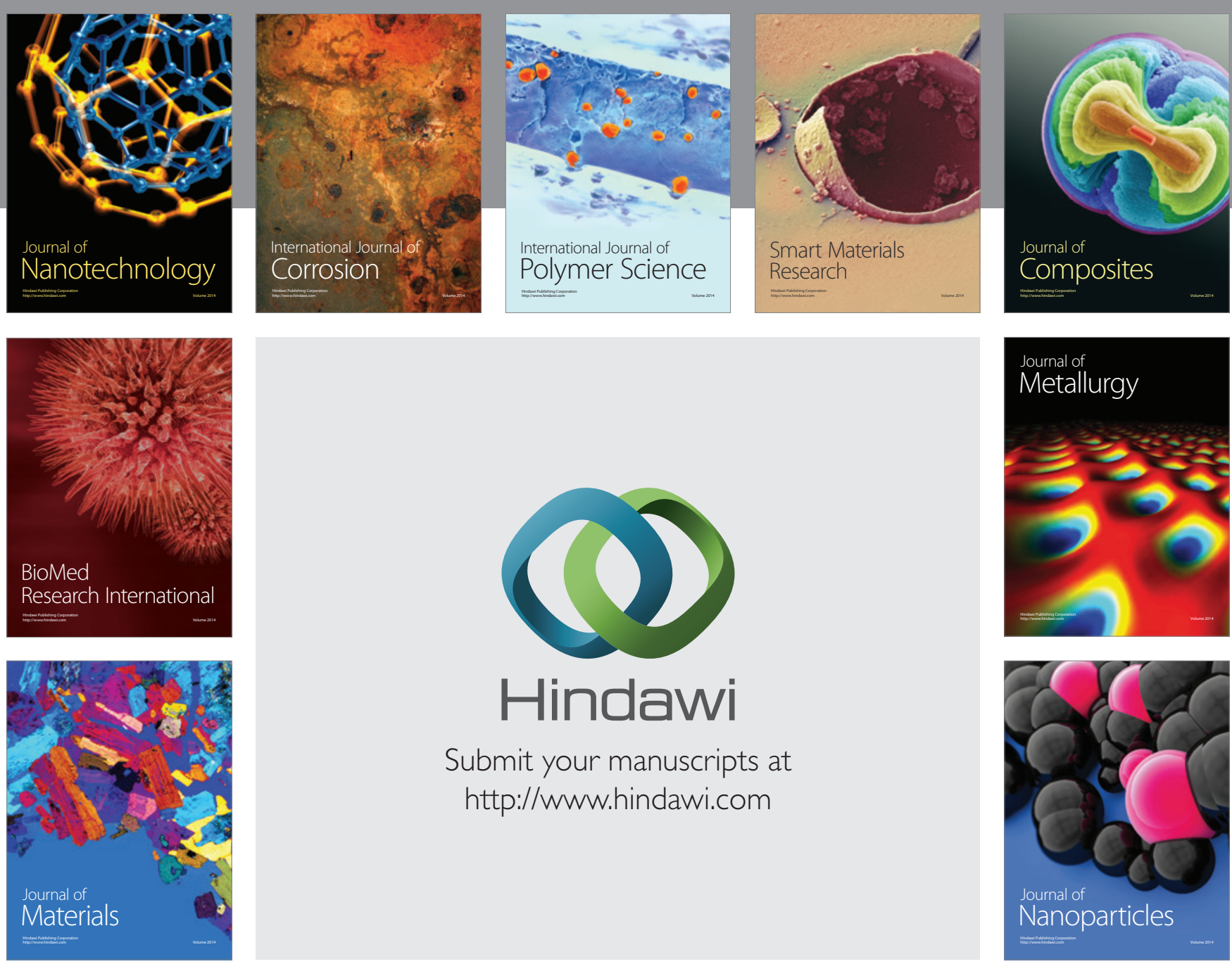

Submit your manuscripts at http://www.hindawi.com
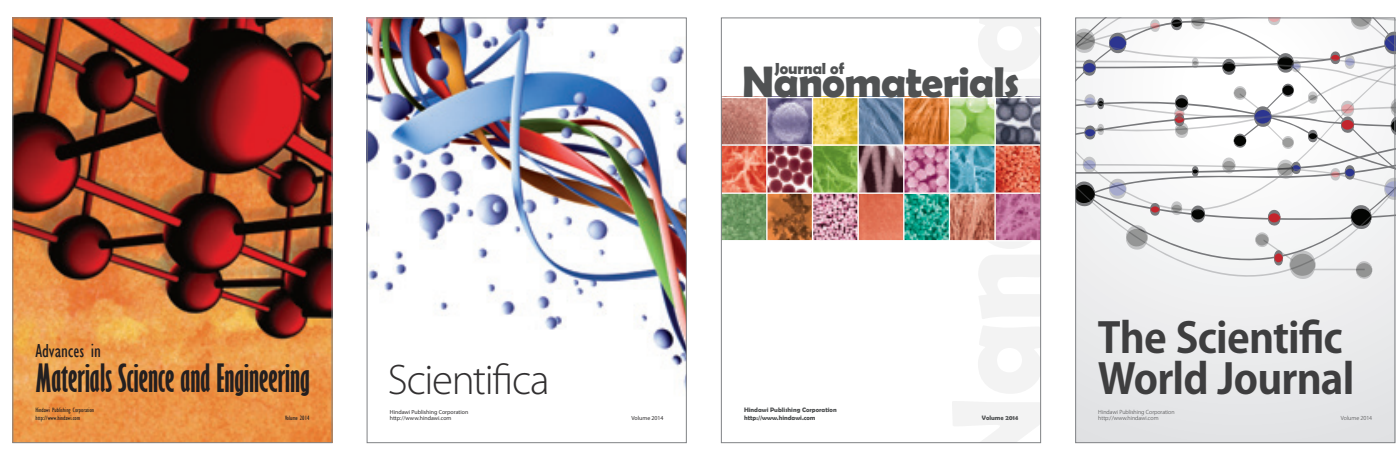

\section{The Scientific World Journal}
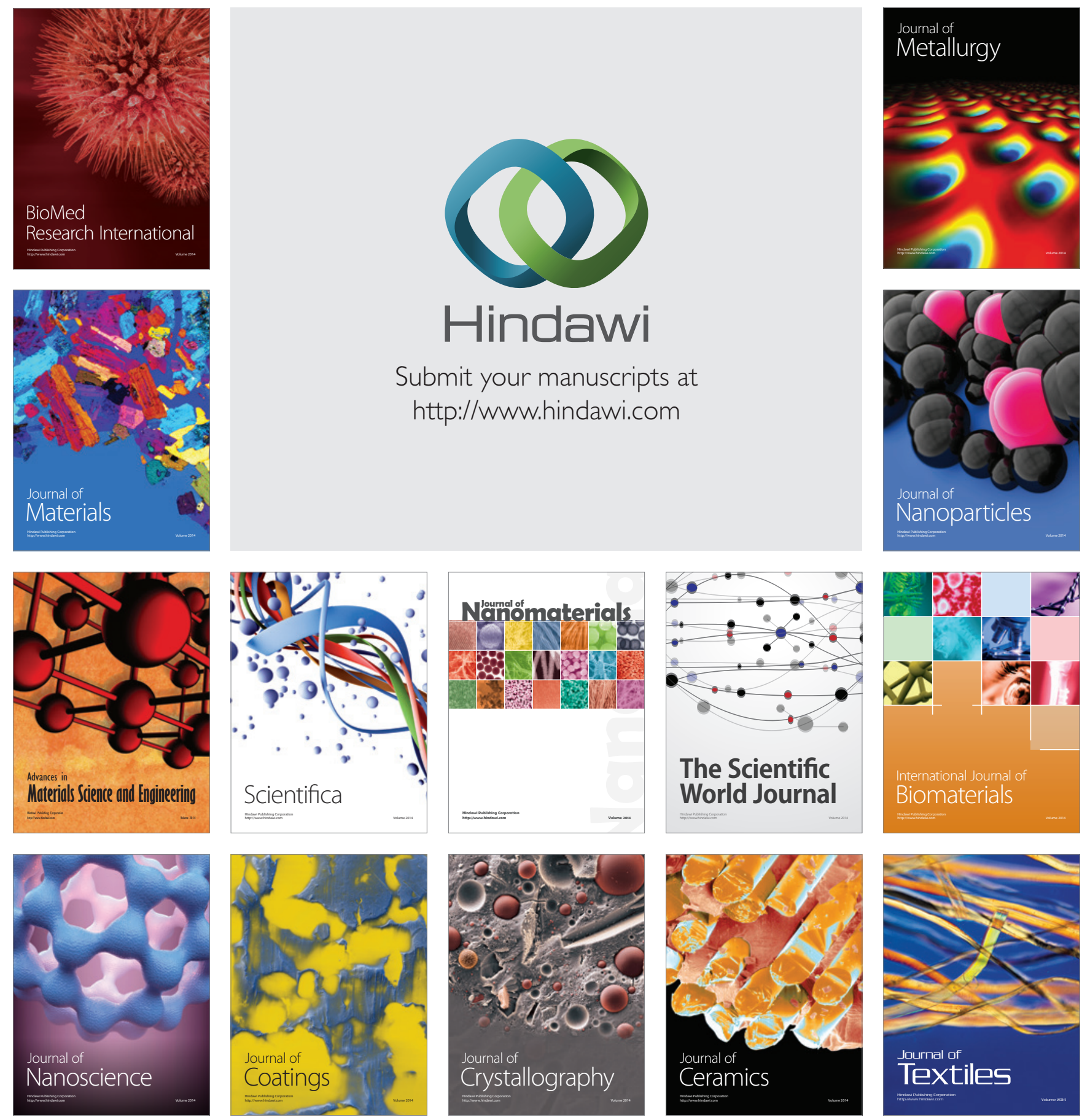